\title{
O LUGAR DA EDUCAÇÃO FÍSICA NO CAMPO: REFLEXÕES SOBRE A OFENSIVA CAPITALISTA E SUAS ESTRATÉGIAS DE DOMINAÇÃO DO CORPO
}

\author{
Aline Silva Andrade Nunes ${ }^{1}$ \\ Adelaide Ferreira Coutinho ${ }^{2}$ \\ Raffaelle Andressa dos Santos Araújo ${ }^{3}$
}

\section{RESUMO}

Este trabalho trata das fundamentações teóricas da sociedade capitalista e suas implicações ao corpo do trabalhador, em especial ao trabalhador do campo, a cultura corporal e seus significados como conteúdo da disciplina Educação Física nos cursos ofertados pelo PRONERA (Programa Nacional de Educação na Reforma Agrária). Trata-se da ampliação da discussão da temática que integrou uma dissertação de mestrado em educação concluída. Portanto, esse estudo procura situar o objeto em sua historicidade e tem como objetivo fazer reflexões sobre o processo constitutivo do corpo e suas interfaces com as categorias trabalho, educação e capitalismo. Para tanto, considera a ofensiva capitalista um sistema que garante o processo de desumanização do homem através de suas estratégias de exploração e dominação do corpo. Como resistência a esse modo de produção, os movimentos sociais e o PRONERA buscam romper com a educação rural e legitimar uma educação de qualidade, que contemple todas as disciplinas curriculares e ressignificando o corpo do trabalhador do campo. Tem como referencial teórico o Materialismo Histórico Dialético; e entre as referências fundamentais para o estudo destacam-se Marx (1993; 2006), Bröhm (2007) e Coletivo de Autores (1992).

Palavras-chave: Capitalismo; Trabalho; Educação; Corpo.

\section{PHYSICAL EDUCATION AND ITS PLACE IN THE COUNTRYSIDE: REFLECTIONS ON THE CAPITALIST OFFENSIVE AND ITS STRATEGIES OF DOMINATION OF THE BODY}

\begin{abstract}
This work deals with the theoretical bases of capitalist society and its implications for the worker's body, especially for rural workers, body culture and their meanings as topics of Physical Education in the courses offered by PRONERA (National Program of Education in Agrarian Reform). A completed master's thesis in education considers the aforementioned context, whose issue is now expanded. Therefore, this study seeks to situate the object in its historicity and aims at proposing reflections on the constitutive process of the body and its interfaces with work, education and capitalism. To do so, it contemplates the capitalist offensive as a system that ensures the process of dehumanization of man through its exploration strategies and domination of the body. As a resistance to this way of production, social movements and PRONERA seek to break with rural education and legitimize quality education, covering all curriculum subjects and giving new meaning to the rural worker's body. It considers Dialectical and Historical Materialism as its theoretical framework; and Marx (1993; 2006), Bröhm (2007) and Group of Authors (1992) stand out from other essential references for this study.

Keywords: Capitalism; Work; Education; Body.
\end{abstract}




\section{INTRODUÇÃO}

A sociedade capitalista contemporânea está marcada por muitas mudanças ocasionadas pelo agravamento das políticas neoliberais. Em um ritmo cada vez mais veloz, o capital e sua lógica incorrigível tornam-se responsáveis pelos impactos negativos que transformam o cenário mundial em palco de contradições e degradações.

O neoliberalismo - seja no plano ideológico, seja no plano econômico desencadeou consequências que têm agravado este cenário: crises econômicas; crescente pobreza; acirramento das desigualdades sociais; desemprego; descaso do Estado quanto ao cumprimento das políticas públicas básicas, como educação, saúde, segurança, transporte, infraestrutura etc., e, o que é pior, aumentou a desesperança.

Esse conjunto de fatores fortalece o discurso da manutenção, do imobilismo, inclusive pelas ações do Estado, tendo em vista controlá-lo e, ao mesmo tempo, incentivar uma subjetividade individualista eficazmente difundida pelo reforço midiático do capitalismo e seu ideário burguês de protagonismo e de empreendedorismo.

Diante dessas contextualizações, este trabalho representa parte de um estudo realizado no Mestrado em Educação - UFMA e trata das fundamentações teóricas da sociedade capitalista e suas implicações ao corpo do trabalhador, em especial ao trabalhador do campo, a cultura corporal e seus significados como conteúdo da disciplina Educação Física nos cursos ofertados pelo PRONERA (Programa Nacional de Educação na Reforma Agrária). Portanto, este estudo procura situar o objeto em sua historicidade e fazer reflexões sobre seu processo constitutivo.

\section{A OFENSIVA CAPITALISTA}

Após as deliberações do Consenso de Washington, nos Estados Unidos, o Brasil também passou por "novas" configurações capitalistas. O fortalecimento do ideário neoliberal pós-Consenso acelerou reformulações que suscitaram profundas alterações no seu funcionamento; posição esta que foi aderida pelo então presidente Fernando Collor, no início da década de 1990, e seguida pelos presidentes que o sucederam.

O discurso dessas reformulações tinha como objetivo demonstrar a incapacidade do Público, colocando o Estado provedor como algo limitado, rígido, anacrônico, ineficaz e incapaz de acompanhar as novas demandas capitalistas. Essa ideologia visou justificar os seguidos ataques que o grande capital vem movendo contra o Estado. Segundo Braz e Netto (2007), no entanto, o objetivo real do capital monopolista não é a "diminuição" do Estado, mas um Estado mínimo para as funções estatais coesivas, precisamente aquelas que contemplam os direitos sociais, e proclamar um Estado máximo para o capital, como se pôde observar durante o agravamento da crise nessa última década.

Por outro lado, o setor privado foi exaltado e, consequentemente, houve o crescimento das propostas privatizantes ${ }^{4}$. O Estado, então, assumiria medidas neoprotecionistas frente ao agravamento das condições de livre concorrência sob a justificativa de aumento da competitividade, intensificando-se o apoio às importações, a expansão das multinacionais e a abertura ao capital externo. Tais providências provocaram o aumento da dívida externa e o desmantelamento de vários setores da economia, a privatização do patrimônio público por valores questionáveis, a diminuição do acesso dos pobres aos serviços básicos (que, em contrapartida, tiveram acesso ao mínimo social das 
políticas de renda), o aumento da força de trabalho na informalidade e desemprego sem precedentes.

Após quatro séculos de existência, o capitalismo continua a construir as bases materiais de sua reprodução, que são: a divisão do trabalho, a propriedade privada, o controle e a exploração sobre a força de trabalho, a produção em escala industrial, a financeirização e sua mundialização.

Historicamente, o proletariado é sujeito primordial desse processo, a partir da contradição existente entre capital e trabalho, ou seja, o trabalhador, apesar de sua organização e de sua luta, permanece realizando as tarefas parcelares, alienado, explorado e subserviente ao capital na produção e na circulação da mercadoria.

No campo, o trabalho capitalizado e sob a forma do agronegócio é dicotomizado, fragmentado e alienado, o que ontologicamente nega a própria essência humana, uma vez que a materialidade do trabalho enquanto ação transformadora da natureza e do homem possui sua dimensão omnilateral.

Sob as perspectivas supracitadas, o trabalho adquire seu caráter alienado pelo forte poder de opressão, pela perda de autonomia do trabalhador e pela desvalorização da produção da própria vida material como ato histórico. Nega-se a centralidade do trabalho enquanto garantia da produção da própria vida humana na sociedade.

O modo de produção capitalista é constituído por contradições que compõem a base estrutural da relação entre o capital e o trabalho:

A divisão do trabalho, na qual estão dadas todas essas contradições e que repousa, por seu turno, na divisão natural do trabalho na família e na separação da sociedade em diversas famílias que se opõem entre si, envolve ao mesmo tempo a distribuição, e, com efeito, a distribuição desigual, quantitativa e qualitativamente do trabalho como de seus produtos (MARX; ENGELS, 2006, p. 59, grifo dos autores).

O trabalho alienado é expressão da negação do homem e das suas relações objetivas e subjetivas com a natureza e com os outros homens, pois, coisificando o trabalho que garante sua existência em mercadoria de valor irrisório, o homem não corresponde aos seus interesses, mas aos do capital.

\subsection{Educação do campo e PRONERA}

Historicamente, a educação rural fincou suas raízes no campo com uma visão de camponês limitada ao trabalhador precarizado, dominado e escravizado, sem reconhecer sua diversidade cultural, seu fazer histórico e sua produção social, impondo a esses sujeitos uma educação voltada a satisfazer as demandas do capitalismo, isto é, uma educação insuficiente e de baixa qualidade, para proporcionar apenas noções básicas de leitura, escrita e cálculo.

Constituindo-se como forte aliada do avanço globalizante do capital no campo, essa educação rural ainda não desapareceu no sentido ideológico de conceber os povos do campo e políticas públicas voltadas a eles. Essas políticas instituídas apresentam-se como alternativas que polarizam ou acentuam as desigualdades já existentes neste espaço, além de usurpar dos trabalhadores que vivem de sua terra e de sua cultura o seu direito a uma educação de qualidade. 
Na década de 1990, um novo paradigma educacional emerge no campo, como fruto da resistência e da organização da luta dos trabalhadores, devido à organicidade dos movimentos sociais e de organizações campesinas como contraponto à educação rural. Assim, a Educação do Campo coloca na pauta nacional as Pedagogias do Movimento ${ }^{5}$, com a premissa pedagógica de que o povo do campo tem uma identidade própria que merece ser respeitada. Tal articulação causou forte pressão sobre o Estado, o que culminou na aprovação de diretrizes e programas governamentais, dentre eles o PRONERA, em 1998.

Surgem, assim, novas reflexões coletivas que apontam para a perspectiva de afirmação da concepção de Educação do Campo, uma educação feita no campo, com pessoas do campo e sobre os interesses do campo, para concretizar uma educação diferente da antiga visão ruralista de instrução. Materializa-se, consequentemente, uma luta que repensa a educação na estrutura organizacional dos movimentos que participam ativamente do processo de construção desse novo conceito de educação.

Isso significa compreender, em suas especificidades, essa atividade essencialmente humana - a educação -, que neste estudo acerca da Educação do Campo é compreendida como parte da realidade enquanto totalidade, já que não pode ser concebida sem o engajamento com suas relações estruturais, principalmente no âmbito da luta de classes.

\subsection{Trabalho camponês: implicações sobre o corpo}

Quando se fala de construção do conhecimento, deve-se ter como referência o entendimento da sociedade e das relações sociais que desencadeiam formas diversificadas de sociabilidade. No caso da sociedade capitalista, tais relações são desenvolvidas por meio da submissão do trabalhador ao domínio de quem possui os meios de produção. No modelo de sociedade capitalista, percebe-se o trabalho como fonte de produção de mercadoria que se faz com a força de trabalho.

Nesse aspecto, não só o trabalho expressa a negação da liberdade do homem, como a "mercadorização" do trabalho ao produzir mercadoria a serviço da ordem burguesa. Marx (1993) ensina que o trabalho não é qualquer tipo de atividade, é uma ação propositada com fins específicos. O homem é e faz parte da materialidade do seu trabalho, pois à medida que modifica a natureza ele também se modifica, ressaltando-se que a concepção de homem que se tem é mais ampla do que os limites do seu próprio corpo.

Nesse processo de modificação do meio ambiente e dele mesmo, o homem não só extrai da natureza os meios necessários à sua subsistência através do trabalho, como também cria o mundo da cultura.

\subsubsection{Corpo como construção histórico-cultural}

O trabalho é mais amplo que a ação do homem sobre a natureza, por ser uma atividade social que historicamente define a essência humana. Conforme se altera o ambiente e o meio físico, produzindo materiais e instrumentos de trabalho, o homem realiza socialmente objetivações, que, por sua vez, constituem-se em novas necessidades, agora incorporadas subjetivamente ao seu ser social, que foi estabelecido historicamente, ou seja, à medida que se incorpora um modo de vida material, cultural e socialmente forjado num longo processo histórico de criação e recriação de formas de produção material (HIDALGO, 2008). 
A compreensão de que o homem não pode ser definido apenas pela dimensão biológica, psíquica, social ou espiritual, mas pela integração de todas elas, constitui um dos fundamentos da construção do corpo e do mundo da cultura.

Essa compreensão integrada do agir do homem sobre a natureza

[...] deu início à construção do mundo humano, do mundo da cultura. Por isso "cultura" implica apreender o processo de transformação do mundo natural a partir dos modos históricos da existência real dos homens nas suas relações na sociedade e com a natureza (ESCOBAR, 1995, p.93, grifo dos autores).

O homem é, deste modo, portador de especificidades culturais no seu corpo. O caráter ontológico dessa afirmativa confirma-se quando se assume, de acordo com as teses marxianas, que o homem não nasce homem, mas se torna homem quando engendrado no contexto das relações sociais. Por isso a necessidade de analisar-se a cultura em sua totalidade, desvelando a aparência e mergulhando na essência que constitui a lógica articuladora da realidade.

Marx (1993) já sublinhava na sua tese fundamental do materialismo histórico dialético que o homem produz seu próprio corpo, uma vez que no trabalho há uma mediação entre a natureza e o homem concreto em um processo ininterrupto da produção do corpo humano. Assim, ele afirmou que:

$\mathrm{O}$ primeiro pressuposto de toda a história humana é naturalmente a existência de indivíduos humanos vivos. O primeiro fato a constatar é, pois, a organização corporal destes indivíduos em, por meio disto, sua relação dada com o resto da natureza. Não podemos, evidentemente, fazer aqui um estudo da constituição física dos homens, nem das condições naturais já encontradas pelos homens [...]. Toda historiografia deve partir destes fundamentos naturais e de sua modificação no curso da história pela ação do homem [...]. Assim, tal como os indivíduos manifestam sua vida, assim, são eles. O que eles são coincide, portanto, com sua produção, tanto o que produzem, como o modo como produzem. O que os indivíduos são, portanto, depende das condições matérias de sua produção. (MARX, 1993, p. 27)

Segundo Daolio (2007), ao se pensar o corpo, não se deve incorrer no erro de vê-lo e pensá-lo apenas como algo puramente biológico ou como um patrimônio universal sobre o qual a cultura marca histórias diferentes. Além das semelhanças ou diferenças físicas, existe um conjunto de significados que cada sociedade escreve nos corpos dos seus membros ao longo da história; significados que definem o que é corpo de maneiras variadas. Segundo ele, "no corpo estão inscritas todas as regras, todas as normas e todos os valores de uma sociedade específica, por ele ser o meio de contato primário do indivíduo com o ambiente que o cerca" (DAOLIO, 2007, p. 39).

O corpo é, então, expressão da cultura na qual está inserido e, conforme vai se socializando, também vai construindo-a. Tal movimento evidencia que o homem está intimamente envolvido em um conjunto de princípios culturais, o que prolonga a visão de corpo concreta, quando inserida no contexto das relações sociais.

Para o Coletivo de Autores (1992), a materialidade corpórea foi historicamente construída e, portanto, existe uma cultura corporal, resultante de conhecimentos 
socialmente produzidos e historicamente acumulados pela humanidade que necessitam ser retraçados e transmitidos continuamente para os outros homens.

É no trabalho que o ser humano garante sua existência, que se relaciona com os outros homens, com a natureza e consigo mesmo. Porém, como analisado anteriormente, este trabalho pode caracterizar-se de forma alienante pelo seu potencial de exploração e dominação do corpo pelo capital.

Quando o capital comanda o processo do trabalho, a acumulação capitalista cria um enorme excedente que fica com os proprietários dos meios de produção. Nesse conjunto de relações mercantis, em que a mercadoria é ponto de partida (intencionalidade) e resultado/processo (produção, circulação, consumo) dessa exploração de força de trabalho, estabelece-se uma relação de estranhamento entre o seu trabalho e a sua própria vida.

É no universo do trabalho que são criados as objetivações materiais e os ideais que transcendem o ser social, visto que, na práxis, existe uma compreensão mais ampla que vai projetá-lo enquanto produto e criação da sua própria atividade. No entanto, nem sempre o sujeito se reconhece nessa materialidade construída e essa inversão constitui o fenômeno histórico da alienação.

Esse ocultamento da exploração do trabalho durante a experiência cotidiana dos trabalhadores é assegurado pela falsa ideia de que o salário remunera todo o seu trabalho. O contrato de trabalho, a jornada pré-fixada, os meios de produção e os espaços físicos de propriedade privada disseminam uma ideologia capitalista que esconde a verdadeira exploração, pois o trabalhador sente a injustiça,

[...] mas não a alcança, na sua experiência cotidiana, a adequada compreensão dela. É somente a análise teórica da produção capitalista, conduzida numa perspectiva de defesa dos interesses dos trabalhadores, que pode esclarecer o verdadeiro caráter da exploração capitalista. (BRAZ; NETTO, 2007, p. 107)

Para o estudo em questão, a cultura corporal, uma das concepções do objeto de estudo da Educação Física por meio da abordagem crítico-superadora, concebe homens e mulheres em suas situações de vida, como as relações sociais no campo, considerando-se a educação e a formação do educador.

Se a cultura é, deste modo, expressão de todo o fazer humano, a cultura corporal é expressão de uma "linguagem, um conhecimento universal, patrimônio da humanidade que igualmente precisa ser transmitido e assimilado pelos alunos na escola". A sua ausência impede que o homem e a realidade sejam entendidos dentro de uma visão de totalidade (COLETIVO DE AUTORES, 1992, p. 42).

Para uma compreensão crítica da realidade, pautada numa visão de totalidade, deve-se situar que a produção material e cultural dos homens define a sua vida social, e nesse processo, outras determinações contribuem para a construção do corpo na história.

Na sociedade capitalista, por exemplo, o processo de acumulação do capital oprime o trabalhador que, ao vender sua força de trabalho, também se vende, "mercadoriza-se", desumanizando sua vida social e colocando-a a serviço do enriquecimento de uma classe. As marcas deixadas no corpo dos trabalhadores possibilitam uma leitura dessa exploração ao longo do domínio cruel e injusto do capital na história moderna. 
Tal contextualização se fez necessária para melhor entender o processo de organização do mundo do trabalho, no que se refere à negação do corpo do trabalhador, e para oferecer bases de modo a se compreender a legitimidade da Educação Física no currículo dos cursos ofertados a jovens e adultos trabalhadores do campo pelo PRONERA, particularmente, nos cursos de formação de educadores e educadoras do campo no Maranhão.

No início do trabalho de cada etapa dos cursos, havia um questionamento acerca do que eles entendiam por Educação Física. Observou-se que uma parte dos educandos a associavam ao esporte de rendimento, aos exercícios cansativos e desnecessários para trabalhadores do campo; outros, por sua vez, relacionavam-na à disciplina, à dimensão recreativa de animação, descontração, relaxamento e confraternização.

Convém, então, dizer que essa concepção não é particular à realidade do campo, pois na cidade, e mesmo nos ordenamentos legais que respaldam as diretrizes pedagógicas do ensino da Educação Física, também predomina a visão da Educação Física como animadora de festividades, destituída de teoria, atividade restrita a condicionamento físico e, por vezes, com horários diferenciados das demais disciplinas para a sua prática. No campo, isso se agrava, principalmente pela não oferta da disciplina, pela ausência de recursos materiais, por uma infraestrutura muitas vezes inexistente, pela falta de professores e, inclusive, pelas justificativas de que não é necessária, uma vez que os sujeitos do campo já exercem atividades laborais de alto esforço físico.

Nota-se, então, que o fetichismo da mercadoria está em todos os segmentos da vida social dos indivíduos, inclusive nos processos de educação do trabalhador, e funciona como estratégia lucrativa, ao transformar em mercadoria tudo o que pode ser consumido pelo trabalhador, que é o caso da educação. Assim, educa-se a força de trabalho (produção e reprodução social), seu corpo na dimensão mais ampla que se tem dele e de seu tempo livre.

Para que a lógica do capital se implemente, muitos valores são veiculados de modo a nublar a consciência dos indivíduos, impedindo-os de perceber que esse sistema requer toda a subjetividade humana a serviço dele. Aí está mais uma ocultação capitalista, o lazer enquanto "liberdade".

Considerando que não é objeto deste trabalho uma análise mais profunda sobre o tempo livre e a negação do lazer do trabalhador do campo e da cidade, discutem-se alguns pontos referentes a essa questão da exploração capitalista sobre o trabalhador em todas as esferas sociais, incluindo o tempo de trabalho e o tempo livre, apenas para contextualizar.

\subsubsection{O trabalho como processo de desumanização do homem}

Na sociedade contemporânea, a reificação do corpo aparece como única alternativa possível em um mundo dominado pela cultura da passividade, do efêmero e do consumo. Desse processo o campo não está isento, especialmente sua juventude, alvo preferencial da propaganda a serviço do consumo.

Enxergar o corpo além dos aspectos biológicos e fisiológicos é reconhecê-lo como criador e produto da cultura, sujeito da vida social, carregado de significados e valores; entendimento este que é essencial para perceber a influência de cada conceito de corpo ao aprofundar-se a questão da cultura corporal na Educação do Campo, tendo em vista que distintos entendimentos desencadeiam concepções diferentes. 
O corpo mercadoria, tido sob a ótica do rendimento físico que obedece a padrões estéticos universais, corresponde principalmente ao referencial da aptidão física. Diferentemente, o paradigma da cultura corporal entende o corpo como patrimônio cultural historicamente construído pelo homem, em uma perspectiva ampla das práticas corporais de significados múltiplos.

Tanto na cidade quanto no campo, o processo de acumulação da mais-valia resulta da superexploração da força de trabalho e, por consequência, da negação do corpo do trabalhador, privando-o de sua liberdade criadora e transformando-o em mercadoria lucrativa para os capitalistas e causando o empobrecimento da classe trabalhadora.

A violência com que se acentuam as condições destrutivas do capitalismo nos dias de hoje exigiu uma reestruturação produtiva que atingiu perversamente as relações produtivas na periferia do capital. Bröhm (2007) diz que é no trabalho que o homem produz e reproduz seu corpo como indício irrecusável de seu pertencimento de classe. Segundo ele, o trabalho marca o corpo a um ponto tal que se pode ler sobre ele os traços da exploração de classes e os estigmas da opressão social.

O corpo do trabalhador do campo, tanto pela forma de trabalho tradicionalmente engendrado sob uma lógica escravista - em que esse trabalhador majoritariamente produz para sobreviver sob condições de grande pobreza -, quanto pelo trabalho subordinado ao grande capital no campo, expressa ainda mais essas marcas da exploração de si e de sua família, retirando-lhes toda a capacidade criadora/criativa e o prazer decorrente desse processo.

O trabalho alienado e subsumido às necessidades produtivas do capital em expansão transforma o trabalhador em escravo de si mesmo e do sistema capitalista, ou seja, é uma atividade que submete o corpo humano à funcionalidade das máquinas, determinando uma hierarquização de classes e sofrimento de toda ordem aos trabalhadores.

O trabalho torna-se, então, apenas uma forma de sobrevivência e não uma atividade que liberte a essência do homem. Tal inversão traz para a vida do trabalhador consequências destrutivas, pois, alienado pelo processo produtivo, pela remuneração e contratos trabalhistas e sob pressão de um exército de reserva, esse trabalhador vende sua vitalidade, priva-se de sua vida social e lazer, produz resultados como se fosse uma máquina para corresponder às imposições do mercado capitalista e se manter vivo e empregável.

Para quem trabalha no campo, nas atividades agrícolas, os sinais de sofrimento e exploração são ainda mais visíveis. Atingidos pelas condições precárias de trabalho, de transporte e de segurança, mal-remunerados, expostos ao sol e na maioria das vezes, expropriados das suas terras pelos latifundiários, essa categoria está exposta a um trabalho penoso e muitas vezes escravo.

Tal qual a realidade da cidade, que submete o proletário ao sacrifício de si mesmo em nome do enriquecimento do explorador, o trabalhador do campo estabelece uma relação de trabalho em que o proprietário dos meios de produção não está sujeito ao trabalho expropriado e sim à posse, com direito à fruição do ócio.

Bröhm (2007) afirma que essa relação desigual determina que o trabalho penoso não afeta somente um corpo de sofrimento ao trabalhador. A produção e a reprodução das relações de produção capitalistas distribuem igualmente os indivíduos segundo uma hierarquia corporal de classe. 
Impedindo os trabalhadores de se apropriarem do trabalho para realização da vida, a lógica mercadológica do corpo impõe

[...] a instituição de uma tecnologia corporal rentável cujo objetivo é integrar o corpo ao universo industrial e, portanto, modelar seu funcionamento por aquele das máquinas. [...] esta imbricação total do corpo produtivo ao sistema da produção maquínico, esta osmose mosntruosa entre o homem e a máquina - a máquina funcionando num modo "inteligente", o homem funcionando de modo maquinal - que caracteriza o modo de produção capitalista (BRÖHM, 2007, p. 353).

O agronegócio é um desses modelos de produção no campo que obedece aos padrões de desenvolvimento da indústria capitalista. Sob a justificativa de "modernizar" o campo e expandir a economia do país no mercado internacional, são estabelecidas condições que acirram as desigualdades sociais, exploram ainda mais a mão-de-obra de homens e mulheres, agrava a degradação ambiental, dentre outras consequências trágicas para os povos do campo.

\section{CONCLUSÃO}

Percebe-se que há uma relação que vincula o modo de produção capitalista - nas dimensões do trabalho alienado, explorado e do desemprego - na cidade à realidade do campo: o trabalhador camponês, a terra, o agronegócio, seus sujeitos e a concentração de riquezas.

Verificam-se ainda no contexto da educação concepções e projetos defendendo o ruralismo pedagógico enquanto política de contenção do homem no campo e o saber descontextualizado. Quanto à concepção de corpo, identifica-se a presença do modelo fetichizado, que transforma o homem e seus significados culturais em mercadoria. Por sua vez, a Educação Física nesses espaços tem procurado articular o conhecimento ao trabalho capitalista, distinguindo o praticar do pensar, estimulando a competição e o rendimento.

Somente com a constituição de um projeto de sociedade socialista, que priorize metas diferentes das citadas acima, será viável estabelecer uma visão de mundo e de educação que possibilite a mediação do trabalho como essência humana; as relações com a terra como possibilidade de produção social, de trabalho digno e, na educação, a qualidade referenciada socialmente.

Considerando tais pressupostos, deve-se instituir a educação para os sujeitos do campo sob o paradigma em construção da Educação do Campo, que percebe o corpo carregado de significados e valores sócio-históricos, criadores e criações da cultura. A Educação Física tendo o objeto de estudo pautado na concepção de cultura corporal, por sua vez, também traz o conceito de corpo e movimento enquanto construção social e histórica.

Socializar conhecimento e formar consciência crítica dos sujeitos do campo, pautada em uma educação que livre os trabalhadores das amarras capitalistas, significa construir espaços coletivos de ressignificação do corpo no trabalho, na cultura e na vida social e política em sua totalidade. 


\section{REFERÊNCIAS}

BRAZ, Marcelo; NETTO, José Paulo. Economia política: uma introdução crítica. 2. ed. São Paulo: Cortez, 2007.

BRÖHM, Jean-Marie. “Depois de mim, o dilúvio!”: imagens da morte e da negação do corpo em Marx. In: NÓVOA, Jorge (Org). Incontornável Marx. Salvador: Edufba; São Paulo: Unesp, 2007.

COLETIVO DE AUTORES. Metodologia do ensino de educação física. São Paulo, Cortez, 1992.

DAOLIO, Jocimar. Da cultura do corpo. Campinas: Papirus, 2007. (Coleção Corpo e Motricidade).

ESCOBAR, Micheli Ortega. Cultura Corporal na escola: tarefas da Educação Física. Motrivivência, Florianópolis, v. 8, n. 8, dez. 1995.

HIDALGO, Angela Maria. De "educação para a responsabilização individual” para "educação e consciência de classe". In: ORSO, Paulino José, GONÇALVES, Sebastião Rodrigues e MATTOS, Valci Maria. Educação e luta de classes. São Paulo: Expressão popular, 2008.

MARX, Karl; ENGELS, Friedrich. A ideologia alemã: Feuerbach - a contraposição entre as cosmovisões materialista e idealista. São Paulo: Martin Claret, 2006.

A ideologia alemã: Feuerbach. São Paulo: Editora Hucitec, 1993.

\footnotetext{
${ }^{1}$ Mestre em Educação (UFMA), integrante do Grupo de Estudos e Pesquisa Pedagógica em Educação Física (GEPPEF), professora de Educação Física do IFMA.

${ }^{2}$ Doutora em Educação (UFRN), integrante do NEPHECC e professora da UFMA.

${ }^{3}$ Doutoranda em Educação (UECE), Mestre em Educação (UFMA), integrante do GEPPEF, professora de Educação Física do IFMA.

${ }^{4}$ As políticas de privatização das empresas estatais tiveram seu auge nos oito anos de governo do presidente Fernando Henrique Cardoso.

5 Na Educação do Campo as Pedagogias do Movimento são identificadas pelos princípios políticopedagógicos dos movimentos sociais do campo: a luta social, a organização coletiva, a terra, o trabalho e a produção, a cultura, a história e a alternância.
}

Recebido: abril/2015 Aprovado: jul/2015 